\title{
MOTRICIDADE CORPORAL COMO MEIO DE RESIGNIFICACÃO DA SEXUALIDADE DO ADOLESCENTE INSTITUCIONALIZADO
}

\author{
Marcelino Viana da Silva Neto \\ Doutorando, CIEC, Instituto de Educação \\ Universidade do Minho, Braga, Portugal \\ marcelinovsneto@gmail.com \\ Andrea Stopiglia Guedes Braide \\ Docente da Escola de Saúde Pública do Ceará, Brasil \\ andreasgbraide@gmail.com \\ Zélia Ferreira Cacador Anastácio \\ Docente CIEC, Instituto de Educação \\ Universidade do Minho, Braga, Portugal \\ zeliaf@ie.uminho.pt
}

Recepción Artículo: 27 octubre 2021

Admisión Evaluación: 27 octubre 2021

Informe Evaluador 1: 28 octubre 2021

Informe Evaluador 2: 29 octubre 2021

Aprobación Publicación: 30 octubre 2021

\section{RESUMO}

0 abuso sexual em adolescentes tem alta incidência e, em sua grande maioria, acontece na própria família. É frequentemente ocultada pela vítima por medo e opressão do abusador. Entre os familiares, existe uma repulsa gerada pelo sentimento de vergonha ou pelo medo de represálias no próprio meio de convivência do abusado e abusador. É sabido que essa condição pode interferir diretamente na sexualidade do sujeito e isso não é diferente com jovens institucionalizados. 0 corpo do adolescente sofre de forma silenciosa e, muitas vezes, o corpo fala por movimentos que sinalizam pavor, castração e até culpa. Por meio do trabalho corporal denominado Psicomotricidade Relacional, o estímulo do corpo é fundamental para que o sujeito possa se expressar de forma segura e até ressignificar situações traumáticas vivenciadas. Através do movimento espontâneo e não verbal com situações provocadas, as repercussões de uma memória corporal vivida de forma traumática podem ser percebidas e reorganizadas. A leitura que traduz o sofrimento na vida de adolescentes institucionalizados através da motricidade corporal pode, portanto, ter um novo estímulo para favorecer a autonomia e sexualidade. Como um marco teórico da Psicomotricidade Relacional, esta atividade que prioriza o movimento do corpo não falado, é uma intervenção saudável à afirmação de identidade e auxilia na boa saúde sexual do adolescente.

Palavras-chave: adolescência; sexualidade; motricidade corporal 


\title{
MOTRICIDADE CORPORAL COMO MEIO DE RESIGNIFICAÇÃO DA SEXUALIDADE DO ADOLESCENTE INSTITUCIONALIZADO
}

\begin{abstract}
Body motricity as a means of resignifying the sexuality of institutionalized adolescents. Sexual abuse in adolescents has a high incidence and, in its great majority, happens in the family itself. It is frequently hidden by the victim for fear and oppression of the abuser. Among family members, there is a repulsion generated by the feeling of shame or fear of reprisals in the own environment of the abused and abuser. It is known that this condition can directly interfere in the sexuality of the subject and this is no different with institutionalized youngsters. The body of the adolescent suffers in a silent way and often the body speaks through movements which signal dread, castration and even guilt. Through the body work called Relational Psychomotricity, the stimulation of the body is essential so that the subject can express him/herself safely and even give new meaning to traumatic situations experienced. Through spontaneous and non-verbal movement with provoked situations, the repercussions of a bodily memory experienced in a traumatic way can be perceived and reorganised. The reading that translates the suffering in the life of institutionalised adolescents through body motricity may therefore have a new stimulus to favour autonomy and sexuality. As a theoretical framework of Relational Psychomotricity, this activity that prioritizes the unspoken body movement is a healthy intervention to identity affirmation and assists in good sexual health of adolescents.
\end{abstract}

Keywords: adolescence; sexuality; body motricity

\section{INTRODUÇÃO}

A problemática de jovens institucionalizados, vítimas de abuso sexual e suas necessidades de atenção psicológica podem ter, na expressividade corporal e terapêutica não verbalizada, uma estratégia prática de tratamento. Com intenção de reconstruir os vínculos afetivos de adolescentes em decorrência de abusos sexuais, este estudo traz uma perspectiva metodológica por meio dos preceitos da Psicomotricidade Relacional como estratégia de cuidado e reafirmação da identidade.

Entende-se a Psicomotricidade Relacional como um meio de intervenção em crianças vítimas de abuso sexual, favorecedora da reconstrução e da ressignificação dos vínculos afetivos. 0 abuso sexual prolongado leva, quase sempre, a criança vitimada a sentir-se depreciada moralmente, perante a sociedade, 0 que a leva a desenvolver uma perda significativa de sua autoestima, por entender que perdeu o seu valor como pessoa, perante 0 mundo e, consequentemente, construindo uma representação distorcida da sexualidade. Algumas crianças abusadas sexualmente podem adquirir dificuldades futuras para manter relações harmoniosas com outras pessoas, transformando-se em adultos que também abusarão de outras crianças, ou passando a se envolver com a prostituição e outros problemas deformantes da personalidade humana (Kornifield, 2000).

0 abuso sexual contra crianças tem crescido assustadoramente, exigindo que se estabeleçam políticas públicas mais efetivas no sentido de conter o crescimento desenfreado desse terrível mal. Nessa perspectiva, os profissionais de áreas diversas, voltadas à atenção ao ser humano (psicólogos, psicomotricistas, psiquiatras, médicos em geral, educadores, juristas e outros) devem ser preparados mais atentamente, no sentido de poderem contribuir com a contenção do abuso sexual, especialmente em relação às crianças, favorecendo uma boa orientação sexual e ajudando a manter um diálogo constante com as vítimas.

Ressalta-se aqui que o trabalho preventivo do abuso sexual deve se iniciar no próprio lar, pois é obrigação fundamental da família orientar seus filhos, de acordo com os princípios da moralidade e da ética. Entretanto, a agitação do mundo atual e as imposições de uma luta humana de pai e mãe em busca de meios materiais indispensáveis à sobrevivência não tem Ihes deixado tempo para assistir ao desenvolvimento gradativo de seus filhos e a ampará-Ios nesse processo em que a aprendizagem na rua é cruel e desumana (Kornifield, 2000).

De acordo com a literatura sobre esse tema, os abusos sexuais são mais frequentes em crianças entre 2 e 15 anos, cujo temor em relação ao adulto é um dos fatores que levam a criança a manter em sigilo essas ocorrências, diante das ameaças que geram o medo de suas queixas não serem consideradas como verídicas. Além disso, 0 sentimento de culpa e vergonha fazem a criança se manter em silêncio e a continuar sendo alvo dos abusos, dos quais, algumas vezes, podem até passar a aceitar (Allender, 1999). 
Considera-se, para efeito deste estudo, que 0 abuso sexual em crianças envolve qualquer manifestação erótica de carícia, em que a criança é colocada como objeto de prazer. Os agentes desses atos, cuja personalidade envolve pedofilia, perversão e psicose, estão espalhados pela sociedade e, muitas vezes, passam despercebidos, podendo até ser familiares próximos e "confiáveis", cujo principal prazer pode ser enganar e desafiar as pessoas que estão à sua volta. Na maioria dos casos, esses abusos ocorrem silenciosamente, dentro da própria casa, envolvendo pessoas próximas: empregados, pais, padrastos, irmãos mais velhos e, até mesmo, a mãe (embora em índice bem menor), além de tios, tias e vizinhos (Andrade, 1998).

Para coibir esses abusos, torna-se imprescindível a atenção permanente às crianças, pois, nesse sentido, não se pode ter segurança nem mesmo dentro de casa, uma vez que os maiores casos de abuso sexual ocorrem dentro da família. Nessa perspectiva, os profissionais de Psicologia e do Serviço Social vêm trabalhando com as vítimas para levá-las ao entendimento de tudo o que lhe aconteceu, procurando minimizar seu sentimento de culpa que, normalmente, a criança sente, ajudando-a a lidar com o trauma, em busca de resgatar a sua autoestima, além de oferecer apoio e suporte à família para que ela se reestruture e passe a colaborar com o trabalho de prevenção à criança vitimada, ensinando-Ihe a se proteger e encorajando-a a denunciar.

Diante dessa problemática, o presente trabalho resultou de uma pesquisa exploratória e descritiva, fundamentada teoricamente em autores que falam do tema, aspectos psicológicos e sociais, com ênfase na psicomotricidade relacional, dentre os quais citam-se Allender (1999), Andrade (1998), Kornifield (2000) e outros. Realizou-se, também, uma pesquisa com crianças e adolescentes que sofreram abusos sexuais e que estão sendo acompanhadas por psicólogos e assistentes sociais, com a intenção de resgatar a sua autoestima e prevenir futuros envolvimentos com prostituição, drogadição e outras atitudes deformantes da personalidade do ser humano.

0 interesse pelo estudo decorreu do envolvimento do primeiro investigador com a atenção psicológica a crianças e adolescentes vítimas de abuso sexual e pela proximidade atual com a Psicomotricidade Relacional que se supõe ser um novo caminho pelo qual se pode trilhar, com a intenção de apoiar a reorganização da autoconfiança para a ressignificação e o fortalecimento de vínculos afetivos de crianças e adolescentes de ambos os sexos, que se sentem traumatizadas em decorrência de abusos sexuais. Acreditando que a intervenção em Psicomotricidade Relacional é uma forma de resgatar a autoestima dessas crianças e adolescentes, optou-se por este estudo cujo objetivo geral foi conhecer aspectos vivenciais pessoais passados e presentes, bem como perspectivas de futuro desses jovens.

\section{OBJETIVOS DA INVESTIGAÇÃO}

0 objetivo geral do estudo foi conhecer diversos aspetos da conceptualização e vivência de crianças e adolescentes vítimas de abuso sexual, o que pode contribuir para delinear o percurso de uma intervenção em Psicomotricidade Relacional.

Em síntese, os objetivos específicos consistiram em:

conhecer a concepção de infância;

conhecer aspetos vivenciais e relacionais da infância;

conhecer concepções sobre a sua vida atual em termos relacionais e escolares;

conhecer as perspectivas dos adolescentes sobre o futuro;

conhecer aspirações relativamente à constituição de uma família.

\section{AMOSTRA E PARTICIPANTES}

0 critério utilizado para constituir a amostra foi a amostragem não probabilística com adolescentes que foram abusadas sexualmente, cujos dados foram registrados no Conselho Tutelar, no período da coleta de dados. Recorreu-se, também, aos dados disponíveis nos relatórios referentes a cada um dos casos que foram disponibilizados seguindo a todos os critérios legais de sigilo e preservação da identidade dos envolvidos no estudo.

Na amostra, a seleção dos entrevistados é irrestrita, disponibilizando elementos facilmente acessíveis pelos pesquisadores, como no caso deste estudo, cujos dados coletados foram submetidos à análise qualitativa, que é 


\section{MOTRICIDADE CORPORAL COMO MEIO DE RESIGNIFICAÇÃO DA SEXUALIDADE DO ADOLESCENTE INSTITUCIONALIZADO}

um método adequado a pesquisas na área das ciências sociais. Assim, procurou-se analisar, à luz da bibliografia consultada e em confronto com a Psicomotricidade Relacional, as respostas e os dados contidos nos relatórios, que disponibilizaram dados de identificação e queixa sobre os factos enquadrados como abusos sexuais em crianças e adolescentes.

A amostra foi constituída por 17 adolescentes na faixa etária entre os 13 e os 17 anos, dos quais 15 eram meninas, enquanto apenas 2 eram do sexo masculino. As meninas estavam na faixa de 13 a 17 anos, enquanto os meninos, entre 13 e 15 anos, no período das entrevistas.

Um fato comum entre esses sujeitos pesquisados é que todos tinham um nível de escolaridade muito baixo, com, no máximo, o Ensino Fundamental e eram oriundos de famílias muito pobres e numerosas, sobrevivendo com uma renda familiar entre um e dois salários-mínimos, no máximo.

As e os adolescentes participantes desta pesquisa eram assistidos pelo Conselho Tutelar de Fortaleza - CE, Brasil, que é uma instituição amparada pelo Estatuto da Criança e do Adolescente (ECA, 1990), exercendo inúmeras funções de caráter administrativo e socioassistenciais, não se impregnando de juridicidade, embora esteja pautado no princípio da legalidade.

\section{Idade das/os adolescentes da pesquisa}

Relativamente à idade, maioria da amostra (53\%) tinha 14 anos, seguindo $18 \%$ com 16 anos, $12 \%$ com 15 , $11 \%$ com 13 e $6 \%$ com 17 anos (Figura 1).

Figura 1. Distribuição dos participantes por idade

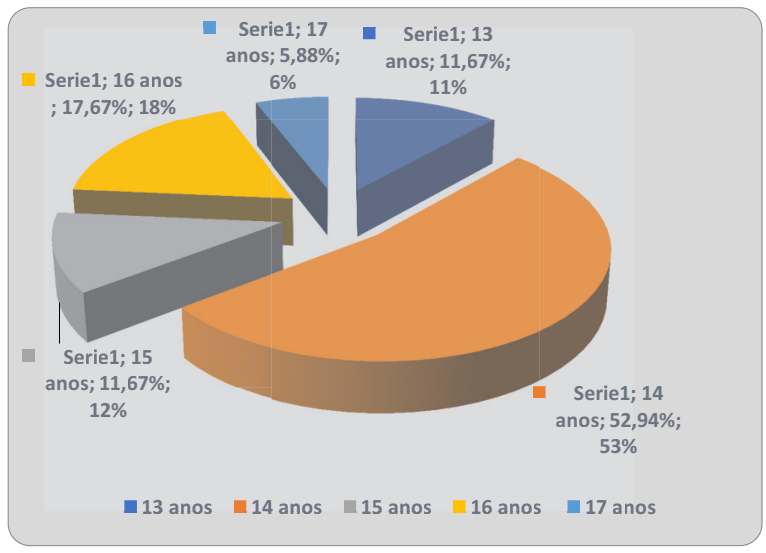

Figura 1. Distribuição dos participantes por idade

\section{METODOLOGIA E INSTRUMENTOS}

0 presente estudo recorreu a um modelo de pesquisa exploratório e descritivo, fundamentado em pesquisa bibliográfica e de campo. Os instrumentos de recolha de dados foram a entrevista semidiretiva e análise de relatórios sobre crianças e adolescentes vítimas de abuso sexual a partir de dados fornecidos pelo Conselho Tutelar de Fortaleza-CE, Brasil. Quanto à natureza, esta pesquisa é definida como exploratória, pois sua intenção é prover a compreensão de um problema enfrentado pelo pesquisador. 0 estudo exploratório permite ao investigador aumentar a sua experiência, aprofundando seu estudo e adquirindo um maior conhecimento a respeito de um problema (Bee \& Bee, 2010).

Para a realização do estudo, foi elaborado um guião da entrevista. Todas as entrevistas foram realizadas individualmente e mediante anonimato. Aos entrevistados, cujos termos de consentimento foram assinados por seus 
pais ou responsáveis, foi assegurada a preservação da identidade, o sigilo sobre as suas respostas e 0 direito de não responder a qualquer pergunta que não fosse do seu agrado.

As questões utilizadas nas entrevistas eram todas abertas, estruturadas de forma a atender aos interesses da pesquisa e assegurando o respeito e a integridade moral e psíquica dos respondentes.

Quadro 1. Guião de entrevista: temas e questões

\begin{tabular}{|c|c|}
\hline TEMAS & QUESTÕES \\
\hline I- Concepção de infância & $\begin{array}{ll}\text { 1- } & \text { O que pensas da tua infância? } \\
2- & \text { O que gostavas mais na tua infância? } \\
3- & \text { O que gostavas menos na tua infância? }\end{array}$ \\
\hline $\begin{array}{l}\text { II- Aspectos vivenciais na } \\
\text { infância }\end{array}$ & $\begin{array}{l}\text { 4.Com quem vivias? } \\
\text { 5.Como era o teu relacionamento com as pessoas } \\
\text { com quem vivias? (pai, mãe, outros) } \\
\text { 6.Tinhas amigos? } \\
\text { 6.1.O que faziam juntos? }\end{array}$ \\
\hline III- Concepção de vida atual & 7. O que pensas sobre a tua vida actual? \\
\hline $\begin{array}{l}\text { IV- Aspectos vivenciais } \\
\text { atuais gerais }\end{array}$ & $\begin{array}{l}\text { 8.Com quem vives? } \\
\text { 9. Como é o teu relacionamento com as pessoas } \\
\text { com quem vives? (pai, mãe, responsável, etc.) } \\
\text { 10. Quem é a pessoa com quem te dás melhor } \\
\text { actualmente? } \\
\text { 10.1.Porquê? } \\
\text { 11. Tens amigos? Que importância têm para ti os } \\
\text { amigos? } \\
\text { 12. Preferes relacionar-te com homens ou com } \\
\text { mulheres? Porquê? } \\
\text { 13. Como descreves a tua vida escolar? Que } \\
\text { importância tem para ti? }\end{array}$ \\
\hline V-Relações amorosas & $\begin{array}{l}\text { 17. Já namoraste alguma vez? } \\
\text { 17.1. Como foi essa experiência? } \\
\text { 18. Actualmente tens namorada (a)? } \\
\text { 18.1.Como é a tua relação com essa pessoa? } \\
\text { 19. Já iniciaste a tua vida sexual? } \\
\text { 19.1. O que pensas sobre isso? }\end{array}$ \\
\hline VI- Concepção de futuro & $\begin{array}{l}\text { 20.Como imaginas a tua vida no futuro? } \\
\text { 21. Que desejas para o futuro profissional? }\end{array}$ \\
\hline
\end{tabular}

Os dados recolhidos através das entrevistas semidirectivas audiogravadas foram transcritos na íntegra e objecto de uma análise qualitativa e quantitativa. Na análise qualitativa, o foco de interesse é amplo e parte de uma perspectiva diferenciada da adotadas pelos métodos quantitativos. Dela faz parte a obtenção de dados descritivos, mediante contato direto e interativo do pesquisador com a situação objeto de estudo. Na pesquisa qualitativa o pesquisador procura entender os fenômenos, de acordo com a situação estudada e, a partir daí, situar a sua interpretação dos fenómenos estudados (Neves,1996).

A abordagem qualitativa favorece a organização dos dados analisados, de forma interpretativa, permitindo a sua análise e explicação à luz de teorias já existentes sobre 0 assunto. Ela visa à construção de uma realidade, 


\section{MOTRICIDADE CORPORAL COMO MEIO DE RESIGNIFICAÇÃO DA SEXUALIDADE DO ADOLESCENTE INSTITUCIONALIZADO}

objeto de estudo das ciências sociais, em um nível de realidade que não pode ser quantificado, trabalhando com 0 universo de crenças, valores, significados e outros construtos (Godoy, 1995).

Os dados quantitativos foram analisados pela estatística descritiva analítica e apresentados em forma de tabelas e gráficos. A pesquisa quantitativa é utilizada quando se necessita medir opiniões, atitudes e preferências como comportamentos. Apenas para melhor visualização dos dados encontrados nos relatórios, optou-se por apresentá-Ios em forma de gráficos construídos no Software Microsoft Excel.

Vale ressaltar que 0 trabalho foi desenvolvido em conformidade com a resolução nํ. 196/96, da Comissão Nacional de Ética em Pesquisa (CONEP), do Conselho Nacional de Saúde (CNS), que trata sobre pesquisas envolvendo seres humanos e do Código de Ética do Psicólogo (2005). Dessa forma, incorporaram-se os processos da bioética, configurados nos ideais de autonomia, não maleficência, beneficência e justiça.

\section{RESULTADOS}

A intenção de resgatar a autoestima e prevenir futuros envolvimentos em comportamentos de risco ficou explícita como objetivo principal desta pesquisa. Constatou-se que os abusos sexuais têm o padrasto e o próprio pai como os principais autores afetando a formação da identidade do sujeito. Os participantes estão conscientes de que passaram por mudanças em seus comportamentos, decorrência dos acontecimentos sofridos em relação aos abusos sexuais e do afastamento da família, além da necessidade de crescimento e amadurecimento prematuros. A estratégia de cuidado desenvolvida com a Psicomotricidade Relacional possibilita a ressignificação do trauma sofrido e, em apoio aos atendimentos psicossociais, ajuda na reorganização da afetividade e do processo de afirmação de identidade para uma vida autónoma.

\section{Resultados - Tema I: concepções da infância.}

"0 que pensas da tua infância?"

Apesar dos sofrimentos e vexames vivenciados pelos adolescentes desta pesquisa, a infância é lembrada, sobretudo, como um período bom de suas vidas. A maioria das verbalizações se reportam a uma relembrança do prazer com as brincadeiras da infância, ressaltando a liberdade, as brincadeiras nas ruas.

Tabela 1. Recordações de infância

\begin{tabular}{lll}
\hline Categorias & $\mathbf{N}$ & $\mathbf{\%}$ \\
\hline Boas recordações & 10 & 58.8 \\
\hline Más recordações & 5 & 29.4 \\
\hline Não respondeu & 2 & 11.8 \\
\hline Total & 17 & 100 \\
\hline
\end{tabular}

\section{"0 que gostavas mais na tua infância?"}

As verbalizações reportam-se à relembrança do prazer com as brincadeiras da infância, ressaltando a liberdade, as brincadeiras nas ruas, que oportunizaram o convívio com os amigos e a vivência de experiências que poderão ter um significado.

\section{"0 que gostavas menos na tua infância?"}

A experiência de isolamento foi a categoria mais apontada. Esse isolamento refere-se ao ficar sozinho em casa. De fato, as crianças vítimas de incesto, geralmente, se isolam e não participam em atividades sociais, quase sempre porque não têm permissão para sair de casa. Nesse sentido, quanto às fofocas, uma entrevistada referiu não gostar dos comentários que muitas pessoas faziam por ser ela muito calada e arredia a essas pessoas. 


\section{Resultados - Tema II: aspectos vivencias da infância (Com quem vivia?)}

Constatou-se que, tomando-se os adolescentes que moram apenas com as mães e aqueles que vivem com a mãe e 0 padrasto, 40\% mantêm contato dentro de casa com a figura materna. Os resultados desta pesquisa indicam que a mãe continua sendo o elemento principal dentro do lar, mas não o único (Tabela 2).

Tabela 2. Com quem vivia na infância

\begin{tabular}{lllc}
\hline \multicolumn{1}{c}{ Categorias } & \multicolumn{1}{c}{ Exemplos } & $\mathbf{N}$ & $\mathbf{\%}$ \\
\hline 1.Família nuclear com ambos os pais & Com pai e mãe & 10 & $58,9 \%$ \\
\hline $\begin{array}{l}\text { 2.Com um dos progenitores e demais } \\
\text { familiares }\end{array}$ & Com a mãe e irmãs & 3 & $17,6 \%$ \\
\hline 3.Com outros familiares & $\begin{array}{l}\text { Com a mãe e } \\
\text { padrasto }\end{array}$ & 3 & $17,6 \%$ \\
\hline 4.Com outros indiferenciados & Com avós e tia & 1 & $5,9 \%$ \\
\hline Total & & $\mathbf{1 7}$ & 100 \\
\hline
\end{tabular}

\section{Relacionamento com as pessoas com quem viviam}

A maioria das verbalizações dos jovens expressaram que sempre mantiveram um bom relacionamento com a mãe e com as demais pessoas de sua convivência (11 - 64\%). Em segundo lugar, encontramos verbalizações sobre um relacionamento irregular (2 - 11,8\%), deterioriação relacional (2 - 11,8\%) e mau relacionamento (2 11,8\%). 0 fato de a maior parte dos participantes, referirem ter tido amigos na infância revela-se como um aspecto muito positivo, visto que as amizades da infância ajudam a criança a construir sua visão do mundo e, muitas vezes, imprimir a coragem necessária para arriscar um pouco mais na descoberta do que está à sua volta. Sobre as brincadeiras realizadas com os amigos, referiram, em maior número, brincar (12-70,6\%), entretanto, alguns que conversavam com esses amigos (3-17,6\%) e uma referência sobre ir à igreja com eles (1 - 11, 8\%).

\section{Resultados - Tema III: 0 que pensas sobre a vida atual?}

0 maior índice de verbalizações incidiu na categoria BOA (11 - 64,7\%) de adolescentes que disseram que denominam sua vida atual, o que pode ser explicado pelo retorno à tranquilidade, após a ocorrência do abuso sexual sofrido. Estar num abrigo para menores em situação de risco pode significar segurança. A vida como triste e difícil (4-23,5\%) pode também ser interpretada em parte pelo motivo de estarem retidas no abrigo. A categoria 'desejo de normalização' (2 - 11,8\%) mostra que os jovens esperam ter uma vida mais tranquila e normal. 0 relacionamento com as pessoas com quem convive atualmente identifica categorias distintas. Verbalizações expressam a ideia de que no relacionamento é, em geral, bom ( $7-41 \%)$, bom com um dos pais ( $3-17,6 \%)$; bom com outros familiars $(2-11,8 \%)$ e difícil $(2-11,8 \%)$.

A existência de amigos é vista em primeiro lugar como fonte de apoio nos estudos e nos momentos difíceis e presença amiga nos momentos difíceis, quando sempre chegam para dar uma ajuda e uma palavra amiga e de incentivo. Em segundo lugar, os amigos são referidos como companhia e contribuindo para evitarem o isolamento. Somente duas verbalizações revelam que um dos entrevistados não sabe expressar qual a importância dos amigos (Tabela 3). 
Tabela 3. Importância dos Amigos

\begin{tabular}{lll}
\hline Categorias & $\mathbf{N}$ & $\mathbf{\%}$ \\
\hline 1.Grande importância & 1 & $5,9 \%$ \\
\hline 2.Apoio & 10 & $58,8 \%$ \\
\hline 3.Quebra de isolamento & 4 & $17,6 \%$ \\
\hline 4.Não sabe/não respondeu & 2 & $11,8 \%$ \\
\hline Total & 17 & $100,0 \%$ \\
\hline
\end{tabular}

\section{Resultados - Tema IV: preferência relacional.}

A maior incidência de respostas recaiu sobre a preferência de amizades com mulheres. Em segundo lugar emerge a ocorrência de respostas que indicam ser indiferente a amizade com homens ou mulheres. Em terceiro lugar, três participantes expressam a ideia da preferência por amigos homens e dois entrevistados abstiveram-se de responder a essa indagação (Tabela 4).

Tabela 4. Preferência relacional

\begin{tabular}{lll}
\hline Categorias & $\mathbf{N}$ & $\mathbf{\%}$ \\
\hline 1. Preferência Masculina & 1 & $5,9 \%$ \\
\hline 2. Preferência Feminina & 10 & $58,8 \%$ \\
\hline 3. Indiferente & 4 & $17,6 \%$ \\
\hline 4. Não responderam & 2 & $11,8 \%$ \\
\hline Total & 17 & $100,0 \%$ \\
\hline
\end{tabular}

\section{Resultados - Tema V: relações amorosas e relações sexuais.}

As experiências de namoro foram referidas como boas, pela maioria dos adolescentes participantes. Alguns se omitiram a responder a essa indagação. Constatou-se que apenas uma menina namorava no momento (Tabela $5)$.

Tabela 5. Relacionamento amoroso

\begin{tabular}{lcc}
\hline Categorias & $\mathbf{N}$ & $\mathbf{\%}$ \\
\hline 1. Importância constituição familiar & 5 & $29,4 \%$ \\
\hline 2.Normal & 5 & $29,4 \%$ \\
\hline 3. Não pensou nisso & 2 & $11,8 \%$ \\
\hline 4.Não é importante & 2 & $11,8 \%$ \\
\hline 5. Não respondeu & 3 & $17,6 \%$ \\
\hline Total & 17 & 100,0 \\
\hline
\end{tabular}




\section{Resultados - Tema VI: concepções de futuro}

As expectativas de futuro desses adolescentes são sempre as mesmas: ter uma profissão digna (14 $87,5 \%$ ), que thes assegure uma vida melhor, com qualidade e tranquila. As profissões almejadas são inúmeras, cada um tem um desejo de ser alguém importante e valorizado socialmente. A consciência de que só através do estudo é possível conquistar uma profissão e ter uma vida digna é geral para a quase totalidade dos pesquisados.

\section{DISCUSSÃO}

Apesar das injúrias sofridas, a maioria das/os adolescentes deste estudo revelou algum otimismo em relação ao futuro, do mesmo modo que afirmou possuir boas recordações da infância. A maioria prefere relacionar-se com mulheres, contam com os/as amigos/as essencialmente para apoio e consideram as relações amorosas importantes para constituir família ou algo normal. Em relação futuro, 0 que mais desejam é teruma profissão digna de modo a ter uma vida melhor. Contudo, algumas adolescentes preferem não responder ou revelam perspetivas menos otimistas. É de salientar também que destas e destes jovens que foram todas/os abusadas/os sexualmente, $58,9 \%$ viveu a sua infância na sua família de constituição nuclear. Mantém-se a tendência de dados reveladores de que a violência sexual ocorre essencialmente na proximidade ou no interior do núcleo familiar. Ocorrendo estudo num contexto interventivo de psicomotricidade relacional, parece termos importantes evidências desta prática na superação do trauma associado à violência sexual, o que é suportado pela literatura.

\section{Psicomotricidade Relacional}

Significativamente, a Psicomotricidade Relacional de Andre Lapierre pauta-se no brincar corporal, no jogo espontâneo como via de acesso ao inconsciente. Anteriormente, autores como Winnicotti entendiam o brincar como espaço em que o sujeito poderia se expressar com autenticidade e liberdade, estando designado ao terapeuta essa habilidade de ampliar a capacidade de intervenção por meio do lúdico. É no brincar, e talvez apenas no brincar, que a criança ou o adulto fruem sua liberdade de criação (Winnicotti, 1989).

Assim como a construção da subjetividade do sujeito transita pelo contacto corporal, é pelo brincar corporal que a criança e 0 adulto podem expressar as suas características mais significativas e as suas potencialidades escondidas nos processos inconscientes. Dessa forma, pela Psicomotricidade Relacional prioriza-se a ação corporal e suas representações simbólicas que, no setting de trabalho, expressarão movimentos análogos aos da vida e assim permitirão à criança, ao adolescente e ao adulto, reencontrar-se com essa memória e redimensionar a sua forma de lidar com ela.

0 corpo é um símbolo porque é a representação mais eloquente da vida e, para além dela, do inconsciente, o corpo, símbolo da vida e do inconsciente é também a partir das suas metáforas, o objeto mais simbolizado do universo, um corpo significante. Diferentemente do corpo imaginário, o corpo significante é sempre parcial, sempre fragmentário, encarnado às vezes numa enfermidade, muitas vezes num pequeno defeito físico ou em qualquer outra característica notável capaz de infletir o curso de uma vida: uma cicatriz no rosto, um pé disforme, um ciciar, uma enxaqueca crónica, uma estrutura pequena ou ainda um nariz desproporcional. Todas essas particularidades físicas tornam-se significantes quando são tão intensamente representativas do sujeito - a seus olhos e aos olhos dos outros - que condicionam a sua realidade afetiva, sexual ou profissional (Nasio, 2009).

Nesse contexto do simbólico e do corpo significante que compõe a teoria da Psicomotricidade Relacional, consideramos dois pontos fundamentais que diferenciam a prática de atividades psicomotoras tradicionais: a transferência e 0 foco no positivo. No conceito de transferência da Psicanálise, bem como 0 seu acesso ao inconsciente manifesta-se por meio da associação livre, a partir do discurso verbal ou da emissão de sons que estimulem a comunicação, tornando-se possível que o/a paciente possa criar um vínculo de confiança com o analista e compartilhar com ele suas demandas, tanto das relações paternas quanto maternas que se revelam por meio da fala e seus implícitos. 0 'dizer', na técnica psicanalítica clássica, é um 'dizer verbal' (Lapierre, 2002). 


\section{MOTRICIDADE CORPORAL COMO MEIO DE RESIGNIFICAÇÃO DA SEXUALIDADE DO ADOLESCENTE INSTITUCIONALIZADO}

Na Psicomotricidade Relacional, para provocar esse 'dizer', liberto dos contrangimentos da realidade e do julgamento, utilizamos o jogo livre, que consideramos como equivalente a "associação livre". Essa atividade espontânea, dando livre curso a imaginação, é reveladora dos conflitos inconscientes e das defesas utilizadas para dele se proteger [...] Esses conflitos são conflitos relacionais que, com maior frequência, dizem respeito às figuras parentais. Conflitos da primeira infância, culpabilizados e repelidos ao inconsciente, que se projetam na relação com o outro cada vez que essa relação apresenta uma analogia com o conflito inicial. Toda patologia é uma patologia da relação. É, então, sobre a relação que precisamos trabalhar (Lapierre, 2002).

É importante ressaltar que, para algumas formas de pensar o saber psicanalítico, 0 analista assume, frente ao paciente, projeções para os papéis masculino e feminino, o que não ocorre na Psicomotricidade Relacional. Psicomotricistas Relacionais homem e mulher são complementares no desenvolver da técnica, estando juntos ou alternando a presença no setting dependendo dos objetivos da sessão e são parceiros relacionais, entrando no brincar e se disponibilizando ao jogo corporal permitindo não apenas que os participantes possam vivenciar momentos de ludicidade, mas também possam aceder a sentimentos e sensações a partir do contacto com 0 corpo tonico-afetivo dos facilitadores, expressão clara das suas demandas pessoais, muitas vezes situada na construção das relações primárias. Os participantes provocam ainda transferências laterais, identificadas provisoriamente em encontros como imagem parental (Lapierre, 2002).

Nessas relações, o contacto com sentimentos ou lembranças desagradáveis das relações parentais ou não são comuns. Porém o foco da Psicomotricidade Relacional está no positivo das descobertas individuais, pois é essa descoberta ou redescoberta que se fará fundamental para a mudança de atitude frente aos obstáculos da vida, a busca pela autonomia e o protagonismo, o que ocorre a partir do contacto com a segurança em si, validada na relação com os adultos, no caso de crianças e adolescentes.

É um prazer, para a criança, ser compreendida na sua necessidade de segurança para ganhar a sua autonomia que, no dia a dia, é proporcionada por pais atentos e verdadeiros educadores. É um prazer construtivo em vez do prazer obtido em angustiá-los, em amolá-los, jogo perverso em geral condicionado por uma organização familiar do tempo ou do espaço a ser reconsiderada (Dolto, 1999).

Nessa discussão acerca da intervenção do masculino e do feminino no setting de Psicomotricidade Relacional como complementares, torna-se necessário destacar a importância, no desenvolvimento da personalidade, da maturação positiva das relações com figuras paterna e materna, assim como com outros referenciais masculino e feminino que surgem na vida da criança, em especial, no entorno de seu contexto psicossocial.

A Psicomotricidade Relacional buscará apoiar, portanto, a criança, 0 adolescente e 0 adulto a construir ou redescobrir esse percurso que tende a levá-Io a autonomia, a autoconfiança, a partir das marcas e dos registos estabelecidos pela relação transferencial com o corpo inconsciente, no setting, dos facilitadores e demais parceiros relacionais, considerando as suas vivências pessoais e demandas particulares no plano da realidade, aprendendo a utilizar as suas potencialidades e agressividade na organização produtiva da sua história por mais difícil que tenha sido.

\section{Violência e Abuso Sexual}

A violência ou abuso sexual na infância e na adolescência são situações em que a criança, ou o adolescente, é usado para satisfação sexual de um adulto ou adolescente mais velho (responsável por ela ou que possua algum vínculo familiar ou de relacionamento, atual ou anterior), incluindo desde a prática de carícias, a manipulação dos órgãos genitais, mamas ou ânus, exploração sexual, voyeurismo, pornografia, exibicionismo, até ao ato sexual, com ou sem penetração, sendo a violência sempre presumida em menores de 14 anos (Abrapia, 1997).

Os dados epidemiológicos sobre o abuso sexual apresentados na literatura brasileira não são abrangentes, correspondendo a locais isolados e amostras parciais. Para Pelisoli, Pires, Almeida e Dell'Aglio (2010), sabe-se que a violência sexual é um crime subnotificado e que, provavelmente, existem mais casos acontecendo de facto 
do que aqueles que chegam ao conhecimento das entidades responsáveis. Segundo Souza e Adesse (2005, cit in Pelisoli, Pires, Almeida \& Dell'Aglio, 2010), o número de casos que chega ao poder judiciário é muito menor do que os que acontecem na realidade. Além disso, os dados levantados em delegacias, conselhos tutelares e ambulatórios não refletem a realidade das ocorrências. Estudos do Instituto Médico Legal (IML) e do Programa de Atenção a Vítimas de Abuso Sexual (PAVAS), em São Paulo, avaliam que apenas 10\% a 15\% dos casos são revelados.

A omissão deve-se ao facto de esse tipo de violência ser marcado por culpa e vergonha, sendo que na maioria das vezes, como ocorre dentro de casa, tal violência permanece silenciosa. Ainda sobre essa questão, Pelisoli, Pires, Almeida e Dell'Aglio (2010, cit in Sousa \& Adesse, 2005) afirmam que o constrangimento, o medo e a vergonha da vítima em denunciar um crime sexual, o medo de perder o emprego e da atitude da sociedade são também fatores apontados na literatura como contributos para a falta de denúncia. Dessa forma, a verdadeira incidência dos crimes sexuais é desconhecida, sendo, assim, um delito de pequena notificação e com ocorrência pouco registrada.

0 agressor, nos casos de abuso sexual intrafamiliar, em 69,6\% dos casos é o pai, em 29,8\% é o padrasto e em 0,6\% é o pai adotivo (Saffioti, 1996). Drezett (2000) analisou 1200 casos de violência sexual documentados no Hospital Pérola Byington de São Paulo, Brasil, constatando que em 84,5\% dos casos de violência sexual contra a criança 0 agressor era conhecido da vítima, sendo que em $21,7 \%$ o pai era 0 agressor, em $16,7 \%$ o padrasto, em $1,6 \%$ o pai adotivo, em $11,6 \%$ era 0 tio, em 10,0\% 0 avô, em $16,7 \%$ o vizinho e em $21,7 \%$ o agressor era outro conhecido da família. Pelisoli, Pires, Almeida e Dell'Aglio (2010) recolheram dados de 2007 da Secretaria Especial de Direitos Humanos - SEDH Brasil - e constataram que a cada 17 mil denúncias decorridas em um ano, 5 mil eram referentes a abuso sexual [...] até 2003, a média diária de denúncias era de 12, enquanto no ano de 2006, quando número 100 foi adotado, essa média passou para 37 denúncias diárias (SEDH 2009). Os dados indicaram que 28,7\% das denúncias são referentes a abuso sexual, 27,8\% a exploração sexual e $45 \%$ a outras formas de violência contra crianças e adolescentes. Destaca-se que ainda $62 \%$ das vítimas eram meninas, $56,5 \%$ tinha entre 0 e 6 anos e que $53 \%$ dos suspeitos eram os próprios pais das vítimas. (Pelisoli, Pires, Almeida \& Dell'Aglio, 2010, p.86).

0 abuso sexual no círculo familiar é bastante superior aos casos de abuso extrafamiliar, sendo que este último ocorre em apenas 15\% dos casos notificados (Flores, 1998), constatando-se que estes casos se mantêm como número menor conforme dados mais recentes informados anteriormente. Sendo o agressor sexual uma pessoa da família, a escola mostra-se como local ideal para deteção e intervenção junto a tais casos. Para isso, os professores devem frequentar programas de capacitação continuada, para que se tornem aptos a identificar as vítimas desse tipo de agressão, entre os seus alunos, pois é uma violência difícil de ser identificada por não deixar, na maioria dos casos, marcas físicas visíveis.

A possibilidade de transitar da passividade da experiência para a atividade e aplicar a outras pessoas a agressão que Ihe foi conferida é, quase sempre, um meio, ainda que inconsciente, de se vingar do mal que lhe foi feito. Assim, estabelece-se um processo defensivo, que tende a se perpetuar pela identificação com o agressor, como uma maneira psíquica de sobreviver ao abuso. A vítima, ao se igualar com o seu agressor e se converter em molestadora, torna o abuso sexual um legado passado à próxima geração de vítimas (Scherer, Machado \& Gauer, 2003).

0 abuso sexual infantil é considerado, pela Organização Mundial da Saúde (OMS, 2003), como um dos maiores problemas de saúde pública. Estudos realizados em diferentes partes do mundo sugerem que $36 \%$ das meninas e $29 \%$ dos meninos sofreram abuso sexual. Entretanto, a sua real prevalência é desconhecida, pois 0 medo das ameaças do agressor ou de punição por parte dos pais, levam as crianças a silenciar, sendo que muitas delas só revelam esses acontecimentos quando se tornam adultas (Braun, 2002). Ainda de acordo com 0 Relatório de Saúde Mundial da OMS, as vítimas são, na maioria dos casos, meninas, adotadas ou aparentadas, havendo problemas de ordem familiar (OMS, 2004). 


\section{MOTRICIDADE CORPORAL COMO MEIO DE RESIGNIFICAÇÃO DA SEXUALIDADE DO ADOLESCENTE INSTITUCIONALIZADO}

De acordo com dados disponíveis pela Fundação da Criança e da Família Cidadã (FUNCI, 2009), na cidade de Fortaleza, capital do Estado do Ceará, de janeiro a abril de 2009, o Conselho Tutelar recebeu 25 denúncias de violência sexual contra crianças e adolescentes, dentre as quais $90 \%$ dos casos aconteceram no seio familiar, em que 0 agressor tinha algum grau de parentesco com a vítima. No entanto, a família da vítima, em muitos desses casos, obriga-a a retirar a queixa para evitar que alguém da família seja punido, o que dificulta 0 enfrentamento da violência sexual no município. Nos demais municípios do Ceará, o enfrentamento da violência sexual contra crianças e adolescentes tem sido feito através do Projeto Sentinela. Esses dados são bastante preocupantes, pois mostram que a violência sexual com crianças e adolescentes é a que tem sido mais denunciada e acompanhada pelo Conselho Tutelar de Fortaleza. É preciso que se leve em conta, também, que o abuso sexual ocorre para os dois sexos, sendo maior a incidência no sexo feminino, até por ser culturalmente o mais aceite, tanto para 0 ato em si, como para a denúncia.

$\mathrm{Na}$ assistência à criança e adolescente vítimas de maus-tratos, há que se considerar que, em aproximadamente $20 \%$ de todos os casos, existe 0 abuso sexual, sempre acompanhado das agressões psicológicas, como em todas as formas de violência nessa faixa etária. Os casos mais frequentes de violência sexual até à adolescência são decorrentes de incesto, ou seja, quando o agressor tem ou mantém algum grau de parentesco com a vítima, determinando muito mais grave lesão psicológica do que na agressão sofrida por estranhos.

0 agressor usa da relação de confiança que tem com a criança ou adolescente e de poder como responsável para se aproximar cada vez mais, praticando atos que a vítima considera inicialmente como de demonstrações afetivas e de interesse. Essa aproximação é recebida, a princípio, com satisfação pela criança, que se sente privilegiada pela atenção do responsável. Este passa-lhe a ideia de proteção e que seus atos seriam normais num relacionamento de pais e filhas, ou filhos, ou mesmo entre a posição de parentesco ou de relacionamento que tem com a vítima. As abordagens, que se tornam cada vez mais frequentes e abusivas, levam a um sentimento de insegurança e dúvida, que pode permanecer por muito tempo, na dependência da maturidade da vítima, da sua estrutura de valores e conhecimentos, além da possibilidade ou não que teria de diálogo e apoio com o outro responsável, habitualmente favorecedor, consciente ou não, da violência.

Quando 0 agressor percebe que a criança começa a entender como abuso ou, ao menos, como anormal os seus atos, tenta inverter os papéis, impondo-Ihe a culpa de ter aceitado os seus carinhos. Usa da imaturidade e insegurança de sua vítima, colocando em dúvida a importância que tem para a sua família, diminuindo ainda mais o seu amor-próprio, ao demonstrar que qualquer queixa da parte dela não teria valor ou crédito. Passa, então, à exigência do silêncio, através de todos os tipos de ameaças à vítima e às pessoas de quem ela mais gosta ou depende. 0 abuso é progressivo; quanto mais medo, aversão ou resistência pela vítima, maior o prazer do agressor, maior a violência (Felizardo, Zürcher \& Melo, 2003).

Em algumas situações, quando o incesto é revelado, a mãe reage com ciúmes, como rival e passa a colocar na filha a responsabilidade pelo ocorrido. Para corroborar com essa prática, estaria a dificuldade de a mãe reconhecer 0 incesto, pois seria o reconhecimento de seu fracasso como mãe e esposa, enquanto 0 abusador usa de todos os meios para manter seus atos em silêncio e encobertos (Kaplan, Sadock \& Grebb, 1997).

Outro fato gerador de impacto dessa violência na estrutura familiar é que 0 incesto é mais frequentemente relatado em famílias de nível socioeconômico inferior e mais facilmente encoberto por pessoas de nível mais elevado (Kaplan, Sadock \& Grebb, 1997). É possível, então, reforçar que o abuso sexual faz parte de um conjunto de rupturas de relacionamentos, numa estrutura familiar doente, que vem do histórico de vida de cada membro dessa família, incluindo 0 agressor, agravando 0 quadro psicopatológico familiar. Tanto a vitimização quanto 0 testemunho estão associados com a presença de sintomas de sofrimento psicológico, como ansiedade, depressão, problemas de sono, pensamentos intrusivos, dificuldade de concentração, entre outros. (Pelisoli, Pires, Almeida \& Della'Aglio, p. 87, 2010).

É preciso que se tenha sempre presente que todas as formas de abuso sexual podem levar à desestruturação evolutiva da criança ou adolescente e que 0 diagnóstico de que não houve penetração vaginal (caracterizando 0 
estupro) não deve ser minimizado, nem conotado como mais brando do que a realidade. Tanto o abuso sexual vaginal ou anal, com ou sem penetração, ou através de outros meios de agressões ligadas à esfera sexual, são formas doentias e perversas de violência à criança e ao adolescente, que deixam marcas definitivas no seu desenvolvimento físico e emocional.

Segundo Kaplan, Sadock e Grebb (1997), as crianças com menos de 3 anos de idade tendem a não produzir uma recordação verbal de traumas ou abusos passados. Contudo as suas experiências podem ser reproduzidas em seus jogos ou fantasias. 0 abuso sexual deve ser considerado um fator predisponente a sintomas posteriores, como fobias, ansiedades e depressão, bem como envolvimento de um transtorno dissociativo de identidade, também conhecido como transtorno de personalidade múltipla com possibilidade de comportamento autodestrutivo e suicida.

\section{CONCLUSÃO}

Percebe-se que as teorias referentes ao jogo simbólico e da metodologia da Psicomotricidade Relacional permitem que o participante; vítima de abuso sexual e, portanto, com uma ferida emocional referente à autoconfiança e à confiança das figuras de referência de vida; possa projetar nos profissionais, figuras masculinas e femininas, as suas demandas inconscientes e ressignificar os vínculos afetivos conforme os preceitos da intervenção dessa abordagem, que se comprova como uma ferramenta de apoio aos atendimentos psicossociais, uma vez que abre 0 espaço para 0 jogo e para a ação de expressar os sentimentos vivenciados, pautando-se nas potencialidades e internalizando as referências positivas no corpo inconsciente e na consciência individual.

\section{FINANCIAMENTO}

Este trabalho foi financiado por Fundos Nacionais através da FCT - Fundação para a Ciência e a Tecnologia no âmbito do projeto do CIEC (Centro de Investigação em Estudos da Criança da Universidade do Minho) com a referência UIDB/00317/2020.

\section{REFERÊNCIAS BIBLIOGRÁFICAS}

Abrapia, Associação Brasileira Multiprofissional de Proteção à Infância e Adolescência. (1997). Abuso Sexual:

Guia para orientação de profissionais da Saúde. Rio de Janeiro: Autores e Agentes Associados.

Allender, Dan B. Lágrimas Secretas. (1999). São Paulo: Mundo Cristão.

Andrade, F.P. (1998). Labirinto do incesto: o relato de uma sobrevivente. São Paulo: Escrituras e Lacri.

Bee, R.; Bee, F. (2010). Feedback. São Paulo: Nobel.

Brasil. (2002). Código Civil Brasileiro. Lei n. 10.406. Brasília: Senado Federal.

Brasil. (1988). Constituição da República Federativa do Brasil. Brasília: Senado Federal, 1988.

Brasil. (1990). Estatuto da Criança e do Adolescente. Lei n. 8.069. Rio de Janeiro: Senado Federal.

Brasil. (1959). Declaração de Direitos da Criança. Rio de Janeiro: Senado Federal.

Dolto, F. (1999). Tudo é linguagem. São Paulo: Martins Fontes.

Drezett, J. Aspectos biopsicossociais da violência sexual. Jornal da Rede Pública, n. 22, p.18-21, 2000.

DSM-IV-TR. (2002). Manual de Diagnóstico e Estatística das Perturbações Mentais. (Tradução ALMEIDA, J. N.) Lisboa: Climepsi.

Felizardo, D.; Zürcher \& Melo, K. (2003). Modelos teóricos de interpretação para violação do incesto: do medo e sombra. Natal: AS.

Flores, R. Z. Definir e medir o que são abusos sexuais. In: Leal, M. F. P.; César, M. A. (orgs.). Indicadores de violência intrafamiliar e exploração sexual comercial de crianças e adolescente Brasília: Ministério da Justiça, 1998.

Funci. Fundação da Criança e da Família Cidadã. (2009). Aumentam denúncias contra violência sexual em Fortaleza. In: CATAVENTO COMUNICAÇÃO E EDUCAÇÃO. É preciso criar rede de atenção que possibilite a construção de uma política municipal. Rede ANDI Brasil. 29 abr.2009. 
Gil, A.C. (1999). Métodos e técnicas de pesquisa social. São Paulo: Atlas.

Godoy, A. S. (1995).Introdução à pesquisa qualitativa e suas possibilidades. Revista de Administração de Empresas, Rio de Janeiro, v. 35, n. 2, p. 57-63, mar./abr., 1995.

Kaplan, H., Sadock, B., Grebb, J. (1997). Problemas relacionados ao abuso ou negligência. In H. Kaplan \& B. Sadock. Compêndio de Psiquiatria. 7.ㄹ ed. Porto Alegre: Artes Médicas.

Kornifield, D. (2000). Vitima, sobrevivente, vencedor: perspectivas sobre abuso sexual. São Paulo, Sepal.

Lapierre, A. (2002). 0 adulto diante da criança de 0 a 3 anos: psicomotricidade relacional e formação de personalidade. 2. ${ }^{\text {a }}$ ed. Curitiba: UFPR / CIAR.

Nasio, J.-D. Meu corpo e suas imagens / J.-D. Nasio; tradução André Telles. — Rio de Janeiro: Jorge Zahar Ed., 2009.

Neves, J. L. (2005). Pesquisa qualitativa: características, usos e possibilidades. Cadernos de Pesquisas em Administração, v. 1, n.3, 2ํㅗ sem., 1996.

OMS. World Health Organization. (2003). Guidelines for medico-legal care for victims of sexual violence.

ONU. Organização das Nações Unidas. (1995). Resolução 40/33. Regras para a administração da justiça na Infância e na adolescência - Regras de Beijing. Assembléia Geral das Nações Unidas. Milão, 29 nov.1985.

Pelisoli, C., Pires, J. P. M., Almeida, M. E., \& Dell'Aglio, D. D. Violência sexual contra crianças e adolescentes: dados de um serviço de referência. Temas em Psicologia - 2010, Vol. 18, no 1, 85 - 97.

Sánchez, P. A; Martinez, M. R.; Peñalver, I. V. (2003). A Psicomotricidade na educação infantil. Tradução Inajara Heubert Rodrigues. Porto Alegre: Artmed.

Saffioti, H. I. B. Quem mandou nascer mulher? estudos sobre crianças e adolescentes pobres no Brasil. Rio de Janeiro: Rosa dos Tempos, 1996. p.139-211. No fio da navalha.

Scherer, C.; Machado, D.S.; Gauer, G.J. (2003). Uma violência obscura: abuso sexual. In: Gauer GJ, Machado DS. (orgs.) Filhos \& vítimas do tempo da violência. Curitiba: Juruá; p. 32-44.

Souza, J.A. (2005). A formação do vínculo afetivo: a questão do apego. Revista Técnica IPEP, São Paulo, v. 5 , n. 1/2,p. 81-98, jan./dez..

Vieira, L.; Batista, M.I.B.; Lapierre, A. (2005). Psicomotricidade Relacional: a teoria de uma prática. Curitiba: Filosofart/Ciar.

Winnicott, D.W. (1989). A criança no grupo familiar. In: Winnicott, D.W. Tudo começa em casa. São Paulo: Martins Fontes. 